\title{
THE IMPLEMENTATION OF PARAMETERS IDENTIFicAtion Of PERMANENT MAgnet SYNCHRONOUS MOTOR IN MC56F8346
}

\author{
BLAHA, P. \& VACLAVEK, P.
}

Abstract: The aim of this paper is to present implementation of fast and simple identification algorithm of permanent magnet synchronous (PMS) motor parameters in fixed point hardware MC56F8346. The proposed identification algorithm operates off-line and on-site which makes it suitable for initial identification of motor parameters with no initial estimate. It is based on excitation using high frequency harmonic signal. Parameter estimation is realized using discrete Fourier transformation. The settings of excitation signal can be modified by the user or they are set automatically by the algorithm. The identification method has been tested in simulation, efficiently implemented in dedicated hardware and successfully tested on a real experimental system. The obtained identification results coincide with the values obtained from the motor manufacturer.

Key words: Permanent magnet motor, control, identification, off-line, on-site
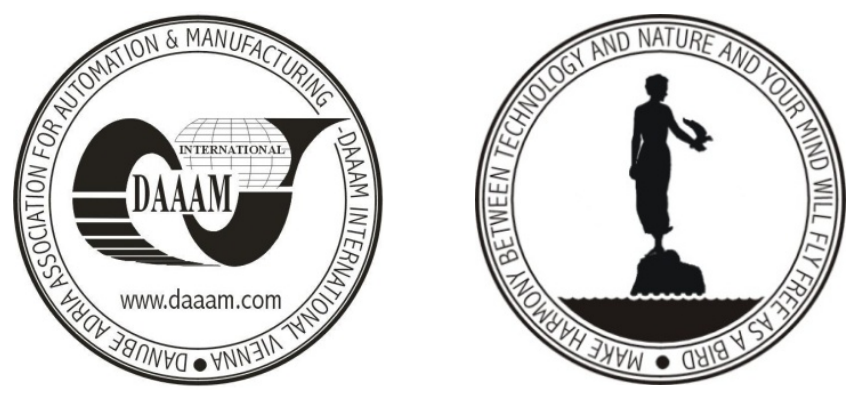

Authors' data: Dr. Blaha, P[etr]; Dr. Vaclavek, P[avel], Brno University of Technology, UAMT VUT v Brne, Kolejní 2906/4, 61200 Brno, CZECH REPUBLIC, 612 00, Brno, CZ, blahap@feec.vutbr.cz, vaclavek@feec.vutbr.cz

This Publication has to be referred as: Blaha, P[etr] \& Vaclavek, P[avel] (2008). The Implementation of Parameters Identification of Permanent Magnet Synchronous Motor in Mc56F8346, Chapter 07 in DAAAM International Scientific Book 2008, pp. 075-084, B. Katalinic (Ed.), Published by DAAAM International, ISBN 978-3901509-66-7, ISSN 1726-9687, Vienna, Austria

DOI: $10.2507 /$ daaam.scibook.2008.07 